\title{
A NATIONAL PHYSICIAN SURVEY OF DIAGNOSTIC ERROR IN PAEDIATRICS
}

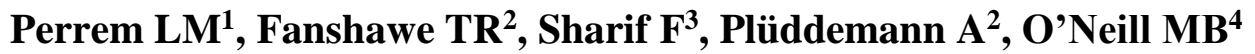

\section{Corresponding Author:}

1. Lucy M Perrem; Department of Respiratory Medicine, Children’s University Hospital, Temple Street, Dublin 1, Ireland. Email: lucyperrem@gmail.com

2. Thomas R Fanshawe, Annette Plüddemann: Nuffield Department of Primary Care Health Sciences, Oxford University, Oxford, United Kingdom. Email: thomas.fanshawe@phc.ox.ac.uk; annette.pluddemann@phc.ox.ac.uk

3. Farhana Sharif; Department of Paediatrics, Midlands Regional Hospital Mullingar, Mullingar, County Westmeath, Ireland. Email: Farhana.sharif@hse.ie

4. Michael B O’Neill; Department of Paediatrics, Mayo General Hospital, Castlebar, Co. Mayo, Ireland. Email: drmichaeloneill@gmail.com

\section{Paediatric Clinical Decision-Making and Diagnostic Error}

Key words: Diagnostic errors, misdiagnosis, physicians practice patterns, attitude of health personnel, clinical competence 
1 A National Physician Survey of Diagnostic Error in Paediatrics

2

\section{What is known}

4 Diagnostic errors are an important source of preventable patient harm and have an $5 \quad$ estimated incidence of $10-15 \%$.

6 - They are multifactorial in origin and include cognitive, system-related and $7 \quad$ situational factors.

\section{What is new}

9 - We identified a low rate of self-perceived diagnostic error in contrast to the 10 existing literature.

11 - Incomplete history and examination, inadequate staffing levels and excessive workload are cited as the principal contributing factors to diagnostic error in this study.

This cross-sectional survey explored paediatric physician perspectives regarding

17 diagnostic errors. All paediatric consultants and specialist registrars in Ireland were

18 invited to participate in this anonymous online survey. The response rate for the study 19 was $54 \%(\mathrm{n}=127)$. Respondents had a median of nine years clinical experience (IQR

20 4-20 years). A diagnostic error was reported at least monthly by 19 (15.0\%)

21 respondents. Consultants reported significantly less diagnostic errors compared to 22 trainees $(\mathrm{p}$ value $=0.01)$. Cognitive error was the top ranked contributing factor to 23 diagnostic error, with incomplete history and examination considered to be the 24 principal cognitive error. Seeking a second opinion and close follow-up of patients to ensure that the diagnosis is correct were the highest ranked clinician-based solutions 
26 to diagnostic error. Inadequate staffing levels and excessive workload were the most

27 highly ranked system-related and situational factors. Increased access to and

28 availability of consultants and experts was the most highly ranked system-based

29 solution to diagnostic error.

30 Conclusions:

31 We found a low level of self-perceived diagnostic error in an experienced group of 32 paediatricians, at variance with the literature and warranting further clarification. The 33 results identify perceptions on the major cognitive, system-related and situational 34 factors contributing to diagnostic error and also key preventative strategies.

35 Abbreviations

36 EHR - Electronic Health Record

37 HSE - Health Service Executive

38 IQR - interquartile range

39 ICU - Intensive Care Unit

40 RCPI - Royal College of Physicians of Ireland

41 Word count 1793

INTRODUCTION

44 Diagnostic error, defined as a diagnosis that is unintentionally delayed, missed or 45 wrong, is an important source of preventable patient harm (1). The true incidence of 46 diagnostic error is difficult to measure but it is estimated that the diagnosis is 'wrong' $47 \quad 10-15 \%$ of the time (2). Diagnostic error is the most prevalent source, accounting for $4832 \%$ to $47 \%$, of paediatric malpractice claims (3-5) In the United States (US) 49 meningitis, appendicitis, specific nonteratogenic congenital anomalies and pneumonia 50 are the most prevalent conditions in paediatric malpractice claims caused by 
51 misdiagnosis (6). Diagnostic errors are multifactorial in origin and include systemrelated and cognitive factors (1).

53 The aim of this survey study was to explore paediatric physician perspectives on 54 diagnostic errors, including self-reported diagnostic error frequency, contributory 55 factors and potential preventative strategies.

METHODS

58

\section{Setting and Participants}

Two hundred and thirty five hospital-based paediatric consultants and registrars across the Republic of Ireland were invited to participate in this study. All paediatric consultants and specialist registrars in Ireland were identified and contacted utilising the Royal College of Physicians of Ireland (RCPI) Faculty of Paediatrics database. The Dean of the Faculty of Paediatrics (RCPI) endorsed the study.

\section{Survey Development and Administration}

The survey was developed following a comprehensive literature review. It was pilot tested among a group of eight paediatric consultants and specialist registrars and survey questions were refined in an iterative process. The anonymous survey was administered using SurveyMonkey ${ }^{\circledR}$ (California, USA), an online survey tool. To maximise the response rate, hard copies of the survey were sent to consultants in addition to an emailed invitation. A second e-mail was sent to non-respondents two weeks after the initial invitation.

\section{Statistical Analysis}

Data were downloaded from SurveyMonkey ${ }^{\circledR}$ and analysed using SPSS 21.0 (SPSS Inc. Chicago, Illinois). Data from paper surveys were manually inputted into SPSS. 
Medians and interquartile ranges (IQR) were used for all descriptive data. The Mann-

Whitney U and Kruskal Wallis tests were used to assess for differences in reported frequencies of diagnostic error. To calculate rankings weighted averages were computed; 3 points were given to a respondents' first choice, 2 points for second choice and 1 point for third choice. All other choices were scored as zero. The average of all of these values for all respondents was calculated. Friedman's Test was used to assess for non-randomness of ranking and test for significant differences among choices.

\section{RESULTS}

\section{5} and both formal and informal for 4 (3.1\%). 
102 The reported frequency of all diagnostic errors and diagnostic errors resulting in 103 patient harm by group are demonstrated in Figure 1. Overall, 19 (15.0\%) respondents 104 reported making a diagnostic error at least monthly, and 14 (11.0\%) respondents 105 reported making a diagnostic error resulting in patient harm at least monthly. 106 Consultants reported significantly less diagnostic errors compared to registrars ( $\mathrm{p}$ 107 value 0.01 ). However, with respect to diagnostic error specifically resulting in patient 108 harm, there was no significant difference between groups ( $p$ value $=0.331)$. Eleven $109(35.4 \%)$ respondents with formal training in diagnostic errors reported making a 110 diagnostic error at least monthly, compared to seven (9.2\%) respondents with no such

111 formal training $(\mathrm{p}$ value $=0.008)$. Years of clinical experience did not significantly 112 affect the reported diagnostic error frequencies $(\mathrm{P}$ value $=0.126)$.

113 Table 1 displays the respondents' rankings of the most common overall factors, 114 specific predisposing factors and possible solutions to diagnostic error. The rankings 115 of the relative contribution of cognitive, systemic and situational factors to diagnostic 116 error and possible solutions were statistically significant across all categories 117 (Friedman test $\mathrm{p} \leq 0.001$ ). When analysed separately, all groups similarly ranked items 118 (data not shown).

119 Figure 1: Self-reported diagnostic error frequency 

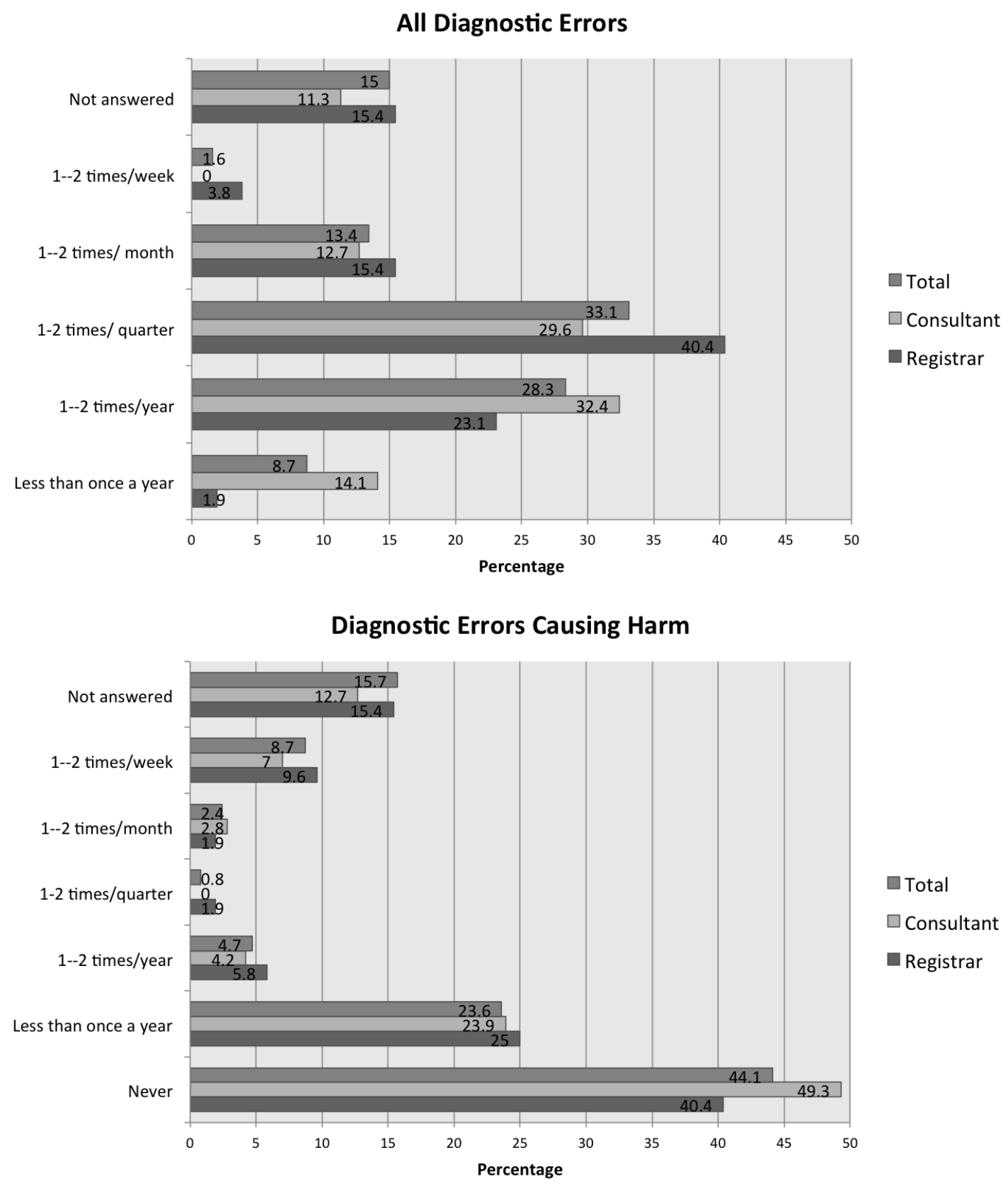


\begin{tabular}{|c|c|}
\hline Most Common Reasons for Diagnostic Error & $\begin{array}{l}\text { Ranking } \\
\text { Range 0-3 }\end{array}$ \\
\hline 1) Cognitive errors such as failing to gather all relevant information & 1.77 \\
\hline 2) Interplay of cognitive and system-related factors & 1.72 \\
\hline $\begin{array}{l}\text { 3) System-related errors such as equipment problems, hospital policy } \\
\text { etc. }\end{array}$ & 1.17 \\
\hline $\begin{array}{l}\text { 4)"No-fault" errors such as those involving rare diseases or unusual } \\
\text { presentations }\end{array}$ & 0.96 \\
\hline \multicolumn{2}{|l|}{ System Related Factors Leading to Diagnostic Error } \\
\hline 1) Inadequate staffing levels and/or experience of healthcare staff & 2.1 \\
\hline 2) Poor communication & 1.57 \\
\hline 3) Delays in accessing sub-specialist expertise when needed & 0.80 \\
\hline $\begin{array}{l}\text { 4) Unavailability of resources due to financial reasons (e.g. MRI, } \\
\text { endoscopy etc.) }\end{array}$ & 0.77 \\
\hline 5) Inadequate information systems (e.g. electronic patient records) & 0.77 \\
\hline 6) Technical problems (e.g. equipment not working correctly) & 0.27 \\
\hline \multicolumn{2}{|l|}{ Cognitive Related Factors Leading to Diagnostic Error } \\
\hline 1) Incomplete history or examination & 1.75 \\
\hline $\begin{array}{l}\text { 2) Failure to consider other possibilities once an initial diagnosis has } \\
\text { been reached }\end{array}$ & 1.42 \\
\hline 4) Over or underestimating the meaningfulness of a clinical finding & 0.76 \\
\hline 5) Drawing an inappropriate conclusion from the available data & 0.63 \\
\hline 6) Missing a symptom or sign that should be noticeable & 0.34 \\
\hline \multicolumn{2}{|l|}{ Situational Factors Leading to Diagnostic Error } \\
\hline 1) Excessive workload & 2.18 \\
\hline 2) Physician fatigue & 1.20 \\
\hline
\end{tabular}




\begin{tabular}{|c|c|}
\hline $\begin{array}{l}\text { 3) Being misled by advice or anticipated advice from other } \\
\text { physicians }\end{array}$ & 0.75 \\
\hline 4) Overconfidence about one's own diagnostic ability & 0.60 \\
\hline $\begin{array}{l}\text { 5) Having an attitude towards the patient either of dislike or of } \\
\text { fondness }\end{array}$ & 0.08 \\
\hline Clinician-based Solutions to Diagnostic Error & \\
\hline 1) Asking for a second opinion & 1.38 \\
\hline 2) Close follow-up of patients to ensure that the diagnosis is correct & 1.33 \\
\hline 3) Increasing time spent in clinical encounters with patients & 1.00 \\
\hline 4) Improving teamwork and communication within healthcare team & 0.98 \\
\hline 5) More training in diagnostic reasoning skills & 0.65 \\
\hline $\begin{array}{l}\text { 6) Increase awareness about diagnostic uncertainty among patients } \\
\text { and families }\end{array}$ & 0.59 \\
\hline System-based Solutions to Diagnostic Error & \\
\hline 1) Increased access to and availability of consultants and experts & 1.58 \\
\hline 2) Electronic patient records & 1.32 \\
\hline 3) Establishing a non-punitive feedback system to learn from errors & 1.18 \\
\hline $\begin{array}{l}\text { 4) Improved feedback pathways to communicate changes in } \\
\text { diagnosis }\end{array}$ & 1.15 \\
\hline $\begin{array}{l}\text { 5) Improved access to electronic diagnostic decision support tools } \\
\text { and reference texts }\end{array}$ & 0.71 \\
\hline
\end{tabular}

122 Table 1: Possible causes and solutions to diagnostic error 


\section{DISCUSSION}

127 This study explored physician perspectives on diagnostic error. Self-reported 128 diagnostic error rates were low in this study. We found that consultants reported 129 significantly less diagnostic errors overall compared to trainees, but a similar 130 frequency of errors causing patient harm. Physician surveys have consistently found 131 that approximately half the respondents encounter diagnostic errors at least 132 monthly.(2) Just $15 \%$ of respondents in our study reported making a diagnostic error 133 at least monthly, regardless of harm, compared to $35 \%(7)$ and $51 \%$ in US 134 paediatrician surveys.(8) In the study by Singh et al(8) $27 \%$ percent of paediatricians 135 had greater than 10 years of clinical experience compared to $53 \%$ in our study. 136 However, the actual diagnostic error rate of respondents is unknown, so this relatively 137 low perceived frequency of diagnostic error may reflect the clinical experience of the 138 sample, signify poor error recognition or overconfidence in one's diagnostic acumen.

139 Factors implicated in the under-reporting of diagnostic errors include recall bias, the 140 time required to submit cases, a natural reluctance to call attention to one's own 141 mistakes, lack of physician reflection on their clinical practice, the fear of provoking a 142 malpractice suit and misunderstanding what is meant by diagnostic error. Additional 143 organizational factors include: lack of safety culture in healthcare setting, poor risk 144 assessment strategies or incident management and the likelihood of patients 145 representing to different healthcare settings and providers.

147 In Ireland, as in other countries, the true incidence of diagnostic error is not well 148 described. In a report by the Irish National State Claims Agency in 2012, diagnosis 149 related adverse events accounted for just $1.8 \%$ of the 1,364 total reported adverse 
events.(9) A systematic review of autopsy studies in paediatric ICUs found a major

151 diagnostic error in 344 (20\%) deaths.(10) However, a UK study in a community

152 hospital setting found a much lower incidence of misdiagnosis in children presenting

153 to the emergency department (ED) with acute illness (5.0\%, $\mathrm{n}=19)$. This was

154 attributed to relatively straightforward clinical cases and experienced treating

155 physicians.(11)

156 Respondents ranked cognitive errors and the interplay of cognitive and system related

157 factors as the most common reasons for diagnostic errors, in keeping with previous

158 research.(1) Similarly to the findings by Singh et al,(8) faulty data gathering by way

159 of incomplete history and examination, was the most highly ranked cognitive factor.

160 "Premature closure", the tendency to favour the initial hypothesis and stop searching

161 for additional possibilities, has been identified as the most common cognitive error in

162 the literature(1) and was highly ranked among respondents in this study. Missing a

163 symptom or sign that should be noticeable was the lowest ranked cognitive factor,

164 which may reflect the clinical experience of the sample. Seeking a second opinion and

165 close follow-up of patients to ensure that the diagnosis is correct were the highest

166 ranked clinician based solutions to diagnostic error in this study.

167 A systematic review by Graber et al(12) summarizes the cognitive interventions

168 aimed at reducing the harm caused by diagnostic errors. Interventions described in

169 this review include improving knowledge and experience with simulation-based

170 training, interventions to improve clinical reasoning and decision-making skills, such

171 as reflective practice and interventions that provide cognitive 'help' including

172 electronic health records (EHR) and integrated decision support and facilitating

173 access to second opinions and specialists.(12) Thirty-four percent of respondents in

174 our sample had received no training, whether formal or informal, on the significance 
of, and factors that may lead to, diagnostic errors, compared to $27 \%$ in the study by

176 Singh et al.(8) Those with formal training reported making significantly more

177 diagnostic errors, suggesting improved awareness of diagnostic error in their clinical 178 practice.

180 Inadequate staffing levels and excessive workload were strongly identified as the 181 leading system-related and situational factors respectively contributing to diagnostic 182 error. Increased access to, and availability of, consultants and experts was the highest 183 ranked system-based solution. These results are not unexpected in the context of a 184 resource deficient Irish health service post economic recession. There is a shortage of 185 consultants across specialties, with one in eight (approximately 300) hospital 186 consultant posts vacant or filled only in a locum capacity. This study identified errors 187 of omission, failing to gather all the relevant information in a case, as the number one 188 cognitive factor related to diagnostic error, this may be explained by time pressures 189 created by inadequate staffing levels.

190 The Electronic Health Record (EHR) was a highly-ranked systems based solution to 191 diagnostic error. However, in a recent US survey of paediatricians, $36 \%$ did not 192 believe that EHR helped to reduce diagnostic errors.(7) Developing a national EHR 193 has been identified by the Health Service Executive (HSE) as a key requirement for 194 the future of delivery of healthcare. An EHR system is proposed for the National 195 Children's Hospital, anticipated to be operational by 2020.

197 According to the Improving Diagnosis in Healthcare report,(13) diagnostic errors 198 harm an unacceptable number of patients, with most people experiencing at least one 199 diagnostic error in their lifetime. The committee outlined goals to improve diagnosis 
and reduce diagnostic error including; facilitate more effective teamwork in the

201 diagnostic process, enhance health care professional education and training, ensure

202 adequate health information technology support, develop and deploy approaches to

203 identify, learn from, and reduce diagnostic errors and near misses in clinical practice,

204 establish a work system and culture that supports the diagnostic process, develop a

205 reporting environment and medical liability system that facilities improved diagnosis

206 through learning from diagnostic errors and near misses.(13)

207 This study has several limitations: 1) the under-reporting of diagnostic errors could

208 not be objectively verified as a survey is not the ideal method of estimating diagnostic

209 error rates 2) the information regarding participants clinical practice including the

210 number of patients seen per physician and time spent in clinical encounters was not

211 known 4) our results are in the context of a resource deficient Irish healthcare system

212 and may not be generalizable to other countries 5) the response rate was 54\% and not

213 all questions were answered by all participants.6) the demographics of non-responders

214 is not known.

\section{CONCLUSIONS}

217 We found a low level of self-perceived diagnostic error in an experienced group of 218 paediatricians at variance with the literature. Tackling diagnostic errors in clinical 219 practice is challenging and requires a multifaceted approach including improving 220 error recognition, physician training in the significance of cognitive errors and 221 addressing system-related factors such as inadequate staffing levels and access to 222 specialist expertise when required. 
226 We would like to thank all the physicians who participated in this survey.

227 Funding:

228 None

\section{Author Contributions}

230 Lucy Perrem designed the survey, collected and analysed the data and wrote the first

231 draft of the manuscript. Thomas Fanshawe was involved in the statistical analysis and 232 approved the manuscript. Farhana Sharif, Annette Plüddemann and Michael O’Neill 233 were involved in the study design and manuscript writing.

\section{Ethical Approval}

235 The survey was anonymous and the content was approved and endorsed by the Dean 236 of the Faculty of Paediatrics on behalf of the Royal College of Physicians of Ireland. 237 RCPI members were informed of the content of the survey prior to their consenting to 238 participation.

\section{Competing Interests:}

240 None

241 REFERENCES:

242 1. Graber ML, Franklin N, Gordon R. Diagnostic error in internal medicine. 243 Arch Intern Med. 2005;165(13):1493-9.

2442 2. Graber ML. The incidence of diagnostic error in medicine. BMJ Qual Saf. 245 2013;22(Suppl 2):ii21-ii7.

246 3. Najaf-Zadeh A, Dubos F, Pruvost I, Bons-Letouzey C, Amalberti R, Martinot 247 A. Epidemiology and aetiology of paediatric malpractice claims in France. Arch of 248 dis child. $2011 \mathrm{Feb}$;96(2):127-30. doi: 10.1136/adc.2010.189209 
4. Sen G, Keene J, Raine J. An analysis of successful litigation claims in childhood fatalities in England. Eur Jour Pediat. 2012 Nov;171(11):1657-60. doi:

251 10.1007/s00431-012-1793-6

252 5. Carroll AE, Buddenbaum JL. Malpractice claims involving pediatricians: epidemiology and etiology. Pediatrics. 2007 Jul;120(1):10-7. doi: 10.1542/peds.2006$\underline{3618}$

255 6. McAbee GN, Donn SM, Mendelson RA, McDonnell WM, Gonzalez JL, Ake JK. Medical diagnoses commonly associated with pediatric malpractice lawsuits in the United States. Pediatrics. 2008;122(6):e1282-e6. doi: 10.1542/peds.2008-1594 7. Rinke M. Primary care pediatricians' interest in diagnostic error reduction. Diagnosis - Landsberg. 2016;3(2).

8. Singh H, Thomas EJ, Wilson L, Kelly PA, Pietz K, Elkeeb D, et al. Errors of diagnosis in pediatric practice: a multisite survey. Pediatrics. 2010;126(1):70-9. doi: 10.1542/peds.2009-3218

9. Oglesby AM. Clinical Adverse Events Notified to the State Claims Agency under the terms of the Clinical Indemnity Scheme. State Claims Agency, 2012.

10. Custer JW, Winters BD, Goode V, Robinson KA, Yang T, Pronovost PJ, et al. Diagnostic errors in the pediatric and neonatal ICU: a systematic review. Pediatric critical care medicine : a journal of the Society of Critical Care Medicine and the World Federation of Pediatric Intensive and Critical Care Societies. 2015 Jan;16(1):29-36. doi: 10.1097/PCC.0000000000000274 11. Warrick C, Patel P, Hyer W, Neale G, Sevdalis N, Inwald D. Diagnostic error in children presenting with acute medical illness to a community hospital. Int J Qual Health Care. 2014 Oct;26(5):538-46. doi: 10.1093/intqhe/mzu066.

12. Graber ML, Kissam S, Payne VL, Meyer AN, Sorensen A, Lenfestey N, et al. Cognitive interventions to reduce diagnostic error: a narrative review. BMJ Qual Saf. 2012 Jul;21(7):535-57. doi: 10.1136/bmjqs-2011-000149

13. National Academies of Sciences Engineering and Medicine. Improving diagnosis in health care. 2015. 